\title{
Compassion: Lessons from the Humanities
}

\author{
Richard E. Deichmann, MD, FACP \\ Former Deputy Head of School - Students, The University of Queensland School of Medicine, Ochsner Clinical School, New Orleans, LA
}

Every commencement speaker strives to inspire the graduates and leave them with one or two ideas that they might carry with them throughout their careers. In reflecting on the many possibilities I might address in my comments to you, I kept returning to the essential characteristics of a wonderful physician. Of these many crucial characteristics, I chose compassion as the most important trait of a great physician and the one I wish to explore with you today. The Ochsner Clinical School regards the compassionate practice of medicine as so crucial to a student's professional formation that an entire course is devoted to these virtues in the senior year. The Accreditation Council for Graduate Medical Education also highlights the importance of compassion as a critical component of its professionalism competency requirement. In my career, I've come to appreciate that the expression of compassion is a uniquely personal connection that touches upon my own humanity as well as that of my patients.

l'd like to explore the nature of compassion from a somewhat nontraditional perspective: the world of the humanities and literature. Artists in the performing arts, visual arts, and written arts all have keen insights into the human condition and talented ways to bring these insights to our attention. Physicians who are authors have particularly unique insights because their work regularly places them in intimate contact with the extreme highs and lows of the human condition. Physician authors have the potential to be particularly revealing sources of inspiration and insights. l'll use some of the insights gained from physician authors who have inspired me so that they may in turn inspire you.

Let's start with defining the word compassion. The word comes from the Latin, meaning "to suffer with." Researchers define it as the feeling that arises when one is confronted with another's suffering and the desire to alleviate that suffering. We know that medical students begin their medical school career with large measures of compassion. However, stress, pressure, and fatigue are all known to wear down one's capacity for compassion. We need to find ways to recognize these negative factors and overcome them to regain our ability to connect with each other on this basic human level.

So what do some of our physician writer colleagues have to teach us about this important human attribute?

Walker Percy was one of the first physician authors to inspire me with his notions about the human condition. Some of his most famous works are The Moviegoer, Love in the Ruins, and The Thanatos Syndrome. Percy was an internationally acclaimed novelist who lived in Covington, across
Lake Pontchartrain, and died in 1990. He himself had endured incredible emotional and physical suffering. His grandfather committed suicide when he was 1 year old, his father committed suicide when Percy was 13, and his mother committed suicide 2 years later when he was 15. After graduating from Columbia Medical School, he trained as a pathologist and contracted tuberculosis after performing an autopsy. At the time, there were no cures for tuberculosis; Percy spent many years in a sanatorium and never was able to practice medicine again. During this time, he began reading the great philosophers and became interested in the basic mysteries of human existence for which science had no explanation.

Percy's many novels explore the existential nature of our lives. His characters are typically quite flawed and the plot lines somewhat fantastical. However, through these fictional devices, he consistently makes a compelling case for us to embrace each other through our humanity in this journey through life. In the novel Love in the Ruins, the protagonist $\mathrm{Dr}$ Thomas More is a psychiatrist with multiple character flaws who is trying to cure society's ills. One of my favorite quotes in the novel is advice Dr Moore gives the reader: "...a note for physicians: If you listen carefully to what patients say, they will often tell you not only what is wrong with them but also what is wrong with you." Here, Percy succinctly shines a light on the interdependency of patient and physician in helping each other become better people and advancing each other's search for happiness and meaning in life.

Another physician writer who has devoted his life to emphasizing the importance of empathy, particularly in today's technological age, is Abraham Verghese. Verghese was born to Indian parents in Ethiopia in 1955. He moved to the United States when war broke out in Ethiopia but went to India for medical school. He applied as an international medical graduate to programs in the United States, was accepted into an internal medicine residency in Johnson City, $\mathrm{TN}$, and later completed a fellowship in infectious disease. His career in infectious disease, dealing with the suffering among AIDS patients, and his early experiences with victims in war-torn Ethiopia significantly influenced his life's work in promoting the importance of humanism in medicine. He founded the center for Medical Humanities and Ethics at the University of Texas-San Antonio and is now the associate chair for the Theory \& Practice of Medicine at Stanford University. In his acclaimed novel Cutting for Stone, protagonist Dr Marion Stone is confronted with massive suffering in the drastically underresourced African community in which 
he practices. He is continually torn between his dedication to his work as a physician, a complex relationship with his twin brother, and his love for a woman who is just beyond his reach.

One of the best quotes in the novel deals with a trick question examiners posed to Dr Thomas Stone, Marion's father, when he was a medical student. Stone is asked, "What first aid treatment in shock is administered by ear?" His answer- "words of comfort"-won the day.

Indeed, "words of comfort" can form the essential elements of our expressions of compassion for those in our care who are suffering. Although we may not have an evidence-based cure or scientific treatment for a given patient's ailment, such expressions can have a very powerful therapeutic effect.

Finally, Paul Kalanithi's work, When Breath Becomes Air, is an emotionally powerful autobiography of his unsuccessful bout with lung cancer. Kalanithi was a gifted writer who graduated from Stanford with a master's degree in English. He then earned an MPhil in the history and philosophy of medicine from the University of Cambridge. He next graduated from Yale Medical School and returned to Stanford for a neurosurgical residency, being interested in the nature of consciousness and what makes us human. However, in 2013, during his residency, Kalanithi was diagnosed with stage IV metastatic lung cancer and died in 2015. His book has become a best seller.

Kalanithi's background as a writer and his astute insights as a neurosurgical resident make for compelling prose-like reading. One insight Kalanithi provides is "Science may provide the most useful way to organize empirical, reproducible data, but its power to do so is predicated on its inability to grasp the most central aspects of human life: hope, fear, love, hate, beauty, envy, honor, weakness, striving, suffering, virtue."

As his health began to deteriorate, he wrote, "The physician's duty is not to stave off death or return patients to their old lives, but to take into our arms a patient and family whose lives have disintegrated and work until they can stand back up and face, and make sense of, their own existence." Once again, this writer focuses on the humanistic aspect of medicine and the priorities we should establish in our interactions with our patients and each other.

So what are some of the main insights from these authors that resonate with me? It seems to me that they are telling us that suffering is inevitable, but at the same time it affords us the opportunity to connect with each other on a deeply human basis and gives us the potential for greater meaning in our lives. These authors encourage us to actively recognize and resist structures and forces that can unattach us from our humanity. Society has entrusted us with a sacred covenant. The bond that the collective members of our society make with us is that they will hold us in high esteem, they will share with us their deepest fears, they will allow us to perform unimaginable acts on their bodies, and they will expose themselves to extreme vulnerability by placing their trust in us. In return, they ask that we try our best to understand and alleviate their suffering and that we not violate this trust. It's a tall order. How can any of us, much less a 28-year-old newly minted resident, understand what it's like for a 53-year-old mom to be dying of metastatic ovarian cancer? Although we may not ever be able to fully understand her plight, don't forget the incredible human impact of expressions of compassion. So I will close with this one big idea I hope you take with you on your medical journey: Always remember the powerful therapeutic effect on both you as a physician and on your patients of "words of comfort."

\section{ACKNOWLEDGMENTS}

Dr Richard Deichmann delivered this address at the November 19, 2016 commencement ceremony for fourth-year students of The University of Queensland, Ochsner Clinical School. Dr Deichmann served as the Deputy Head of School - Students for the Ochsner Clinical School from its inception in 2009 through 2016. Ochsner has established the Richard E. Deichmann Professorship in Primary Care in his honor. 